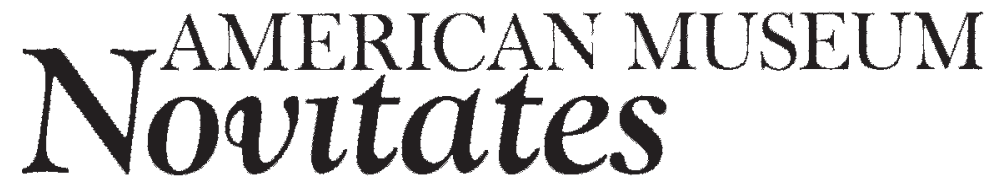

PUBLISHED BY THE AMERICAN MUSEUM OF NATURAL HISTORY CENTRAL PARK WEST AT 79TH STREET, NEW YORK, NY 10024 Number 3571, 11 pp., 3 figures

\title{
Discovery of the First Early Cenozoic Euprimate (Mammalia) from Inner Mongolia
}

\author{
XIJUN NI, ${ }^{1,2}$ K. CHRISTOPHER BEARD,${ }^{3}$ JIN MENG $^{2}{ }^{2}$ YUANQING WANG,${ }^{1}$ \\ AND DANIEL L. GEBO ${ }^{4}$
}

\begin{abstract}
Although it is widely thought that euprimates originated in Asia, the fossil record of early euprimates remains sparse there. We describe herein a new omomyid euprimate, Baataromomys ulaanus, n. gen. et sp., based on an isolated right lower $\mathrm{m} 2$ from Bumbanian strata at Wulanboerhe in the Erlian Basin of Inner Mongolia, China. In terms of the size and proportions of $\mathrm{m} 2$, Baataromomys ulaanus is intermediate between Eurasian and North American species that are usually assigned to Teilhardina. Morphologically, $\mathrm{m} 2$ of Baataromomys differs from that of Teilhardina and North American small-bodied omomyids (including Anemorhysis, Tetonoides, Trogolemur, and Sphacorhysis) in having a smaller paraconid that is less fully connate with the metaconid, a lower entoconid, a weaker crest connecting the metaconid with the entoconid, and a weaker buccal cingulid. The new taxon is much smaller and lower crowned than Steinius, a genus commonly regarded as a basal omomyid. Despite the substantial difference in size, the $\mathrm{m} 2 \mathrm{~s}$ of Baataromomys and Steinius share some important features, including a very broad talonid basin and a relatively low hypoconid and cristid obliqua. Given its early occurrence and primitive anatomy, Baataromomys may eventually help to clarify the phylogenetic relationships among basal omomyids, but more complete specimens will be required to test this possibility. Baataromomys brandti from the basal Wasatchian zone Wa-0 in the northern Bighorn Basin, Wyoming, was previously allocated to Teilhardina. However, several dental features shared by $B$. brandti and $B$. ulaanus suggest that they are closely related. The co-occurrence of Baataromomys in Asia and North America indicates that small-bodied euprimates were able to dispersal across the Beringian region near the Paleocene-Eocene boundary.
\end{abstract}

\footnotetext{
${ }^{1}$ Institute of Vertebrate Paleontology and Paleoanthropology, Chinese Academy of Sciences, Beijing, 100044, China (nixj@amnh.org).

${ }^{2}$ Division of Paleontology, American Museum of Natural History.

${ }^{3}$ Section of Vertebrate Paleontology, Carnegie Museum of Natural History, Pittsburgh, PA 15213.

${ }^{4}$ Department of Anthropology, Northern Illinois University, DeKalb, IL 60115.
} 


\section{INTRODUCTION}

Euprimates, or primates of modern aspect, include living lemurs, lorises, tarsiers, and anthropoids, as well as extinct taxa such as adapiforms and omomyids that are closely related to them (e.g., Szalay and Delson, 1979; Szalay et al., 1987; Rose and Bown, 1991; Rose et al., 1994). To date, the oldest undoubted euprimate fossils have been recovered from earliest Eocene strata in North America, Europe, and Asia (Gingerich, 1986, 1993; Ni et al., 2004). One potential exception, the poorly documented Altiatlasius koulchii from the late Paleocene of Morocco, is often debated as the world's only known Paleocene euprimate (Sigé et al., 1990; Godinot, 1994; Hooker et al., 1999; Beard, 2006). The relatively modern anatomy, high taxonomic diversity, and broad geographic range of earliest Eocene euprimates suggest that the group as a whole originated sometime before the beginning of the Eocene. This conclusion is corroborated by molecular approaches to phylogeny reconstruction, which typically recognize euprimates as one of three living members of the Euarchonta, along with tree shrews (Scandentia) and flying lemurs (Dermoptera) (e.g., Eizirik et al., 2004).

Given the wide geographic distribution of the earliest fossil euprimates, it is not surprising that specialists have so far failed to reach any consensus regarding their ancestral place of origin. The hierarchically nested position of euprimates within the superodinal clades Euarchonta and Euarchontoglires, whose other principal members are all widely thought to have originated in Asia, points toward an Asian origin for euprimates as well (Beard, 1998, 2006; Beard and Dawson, 1999; Ni et al., 2005). Despite the strong biogeographic signal provided by this phylogenetic context, some recent workers continue to advocate a Gondwanan origin for euprimates (e.g., Miller et al., 2005).

Although phylogenetic evidence suggests that euprimates originated in Asia, the fossil record of early euprimates remains sparse there. The phylogenetic affinities of Altanius orlovi, a tiny species known from Bumbanian strata in the Nemegt Basin of Mongolia, are currently disputed. Originally described as an omomyid (Dashzeveg and McKenna, 1977),
Altanius has more recently been interpreted as either a basal euprimate or a plesiadapiform (Rose and Krause, 1984; Gingerich et al., 1991; Beard and Wang, 1995; Ni et al., 2005). Aside from the specimen described here, the only other Bumbanian omomyids described to date are Kohatius and Teilhardina asiatica. Kohatius is a poorly documented omomyid from the Kuldana Formation of northern Pakistan that apparently includes multiple species, only one of which, $K$. coppensi, has been named (Russell and Gingerich, 1980, 1987; Thewissen et al., 1997). The phylogenetic relationships of Kohatius remain unclear. Teilhardina asiatica is based on a partial skull and relatively complete lower dentition from the Lingcha Formation in Hunan Province, China (Ni et al., 2004). According to the phylogenetic analysis of $\mathrm{Ni}$ et al. (2004), T.asiatica is closely related to $T$. belgica, a species that occurs in earliest Eocene strata of Belgium and France. In agreement with Szalay (1982), Ni et al. (2004) found that North American species that are often referred to Teilhardina may actually be more closely related to younger and more derived North American omomyids, such as Tetonius, Tetonoides, and Anemorhysis. With the exception of "Teilhardina" brandti, which was originally described as the earliest Teilhardina from North America (Gingerich, 1993) and is transferred to the new genus from Inner Mongolia here, systematic revision of these North American species is beyond the scope of this study. We provisionally refer them to Teilhardina (e.g., as "Teilhardina" americana) in this paper.

The new euprimate was discovered by screenwashing matrix from the Gomphos bed at Wulanboerhe in the Erlian Basin of Inner Mongolia in 2003. Meng et al. (2004) described dental and postcranial remains of the gliriform mammal Gomphos elkema from this site, which they called "Huheboerhe". The locality is close to the site "7 miles southwest $\left(235^{\circ}\right)$ of Camp Margetts" of the Central Asiatic Expeditions. Locality and stratigraphic data for Wulanboerhe have been published (Meng et al., 2004; Bowen et al., 2005). New field observations indicate that Paleogene beds of the Wulanboerhe- 
Huheboerhe-Nuhetingboerhe area consist of three lithological units: the Nomogen, Arshanto, and Irdin Manha formations. At the Wulanboerhe transect, only the Nomogen and Arshanto formations are present, contrary to Meng et al. (2004) and Bowen et al. (2005). The Gomphos bed occurs in the upper part of the Nomogen Formation, the lower part of which yields a typical late Paleocene (Gashatan) fauna, characterized by the presence of Lambdopsalis, Prionessus, and Palaeostylops. Immediately above the Gomphos bed are red beds that contain a species of perissodactyl similar to Pataecops parvus and an arctostylopid similar to, but significantly larger than, Palaeostylops macrodon. We follow Meng et al. (2004) in referring the Gomphos bed to the Bumbanian Land Mammal Age.

Institutional abbreviations used in this report are as follows: IVPP, Institute of Vertebrate Paleontology and Paleoanthropology, Chinese Academy of Sciences (Beijing, China); MNHN, Museum National d'Histoire Naturelle (Paris, France); UM, University of Michigan Museum of Paleontology (Ann Arbor, Michigan); USGS, United States Geological Survey (Denver, Colorado); USNM, United States National Museum of Natural History (Washington, D.C.); UW, University of Wyoming Geological Museum (Laramie, Wyoming).

\section{SYSTEMATIC PALEONTOLOGY}

$$
\text { PRIMATES LINNAEUS, } 1758
$$

OMOMYIDAE TROUESSART, 1879

Baataromomys, new genus

TyPe SPECIES: Baataromomys ulaanus, new species.

Diagnosis: Smaller than all other omomyids except Teilhardina, Anemorhysis, Tetonoides, Trogolemur, and Sphacorhysis. m2 differs from that of Trogolemur, Sphacorhysis, Anemorhysis, and Tetonoides in having a smaller paraconid that is less fully connate with the metaconid; a lower, less projecting entoconid; a much weaker crest connecting the metaconid with the entoconid; a weaker buccal cingulid; and in lacking a mesially expanded and shelflike paracristid. $\mathrm{m} 2$ differs from that of Teilhardina asiatica, T. belgica, and North
American "Teilhardina" species in having a smaller paraconid that is more closely appressed to the metaconid, and a relatively lower hypoconid and cristid obliqua. $\mathrm{m} 2$ further differs from that of North American "Teilhardina" species in having a lower entoconid, a much weaker crest connecting the entoconid with the metaconid, and a weaker buccal cingulid.

InCLUDED SPeCIES: Teilhardina brandti Gingerich, 1993:322.

Geological Range: Bumbanian of Inner Mongolia and earliest Wasatchian (Wa-0) of Wyoming.

EтумоLogy: Baatar, Mongolian, hero, widely used as Mongolian first name; and omomys, Greek, shoulder-mouse.

\section{Baataromomys ulaanus, new species figure 1}

HoLOTYPE: IVPP V14614, an isolated right m2; only known specimen.

Type Locality and Age: Wulanboerhe, Erlian Basin, Inner Mongolia. Bumbanian of Inner Mongolia.

Diagnosis: $\mathrm{m} 2$ differs from that of $B$. brandti in having a weaker paracristid and a paraconid that is more lingual and less mesial in position.

Eтymology: Ulaan, Mongolian, red. The only known specimen was recovered from a prominent Bumbanian red bed in the Erlian Basin.

\section{DESCRIPTION}

The single isolated right lower molar (fig. 1) can be confidently identified as $\mathrm{m} 2$ because its trigonid is mesiodistally compressed and lingually closed. The tooth as a whole is remarkably bunodont and lowcrowned, and most of its individual cusps and crests are relatively blunt and rounded. The molar has a relatively square occlusal outline, being $1.79 \mathrm{~mm}$ long, $1.47 \mathrm{~mm}$ wide at the trigonid, and $1.52 \mathrm{~mm}$ wide at the talonid. In terms of its size and proportions, $\mathrm{m} 2$ of Baataromomys ulaanus falls between samples of Eurasian Teilhardina and North American "Teilhardina" (fig. 2). 


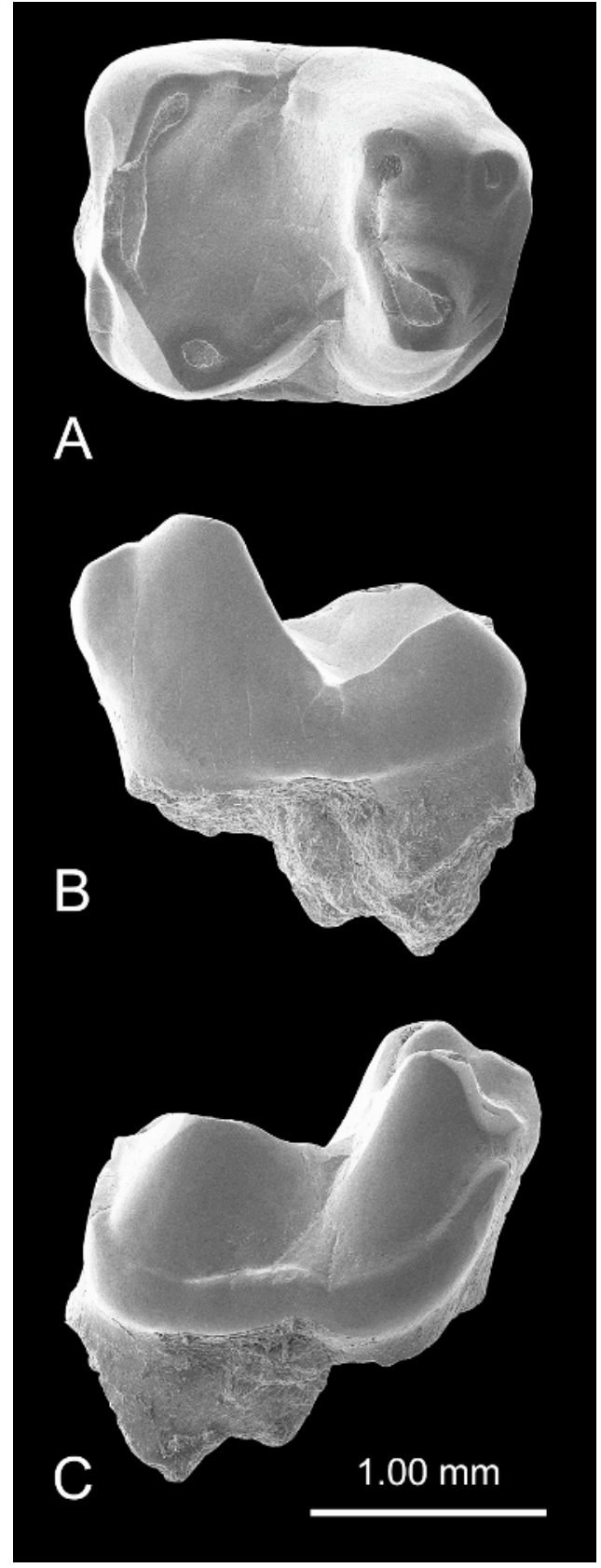

Fig. 1. Baataromomys ulaanus, n. gen. et sp., holotype, IVPP V14614, isolated right $\mathrm{m} 2$. A, Occlusal view; B, lingual view; C, buccal view. Scale bar indicates $1.00 \mathrm{~mm}$.
The trigonid as a whole is slightly inclined mesially. The weakly developed paracristid descends the mesial face of the protoconid before turning lingually to unite the latter cusp with the paraconid. The tip of the protoconid and the buccal arm of the protocristid are worn to expose the dentine, forming a small depression that tapers distolingually. The metaconid is roughly the same size as the protoconid and is situated almost directly lingual to the latter cusp. Its distolingual corner forms a blunt and insignificant ridge, the postmetacristid, that descends the lingual face of the postvallid. The mesial surface of the metaconid is smooth, bearing no trace of a premetacristid. The lingual arm of the protocristid projects buccally from the metaconid, meeting the buccal arm of the protocristid near the midline of the tooth. A transverse line of dentine joins the tip of the metaconid with the lingual arm of the protocristid. The wear facets on the protocristid suggest that the crest was very blunt, and that its lingual and buccal arms probably did not form a continuous shearing crest. The paraconid is very small, occurring at the mesiolingual corner of the trigonid. A tiny pit of dentine is exposed at the apex of the paraconid, indicating that the cusp was low even when it was unworn. No crest connects the paraconid and metaconid. The topography of the internal part of the trigonid is unusual in that the region between the protoconid and metaconid is actually elevated above the level of the protocristid and paracristid.

The talonid is longer and slightly wider than the trigonid. The hypoconid is the dominant cusp, but it and the cristid obliqua remain relatively low and blunt. The lingual surface of the hypoconid is smooth and slopes down to the talonid basin. Its buccal and distal surfaces are continuous, forming a rounded distobuccal corner. The cristid obliqua joins the distal wall of the trigonid beneath the protoconid, resulting in a shallow hypoflexid. The buccal arm of the postcristid is low and blunt, connecting the hypoconulid with the cristid obliqua at about a right angle. The tip of the hypoconid is worn to expose a small round pit of dentine. The cristid obliqua is slightly worn, exposing a tiny line of dentine. The entoconid forms the distolingual corner of the talonid. 

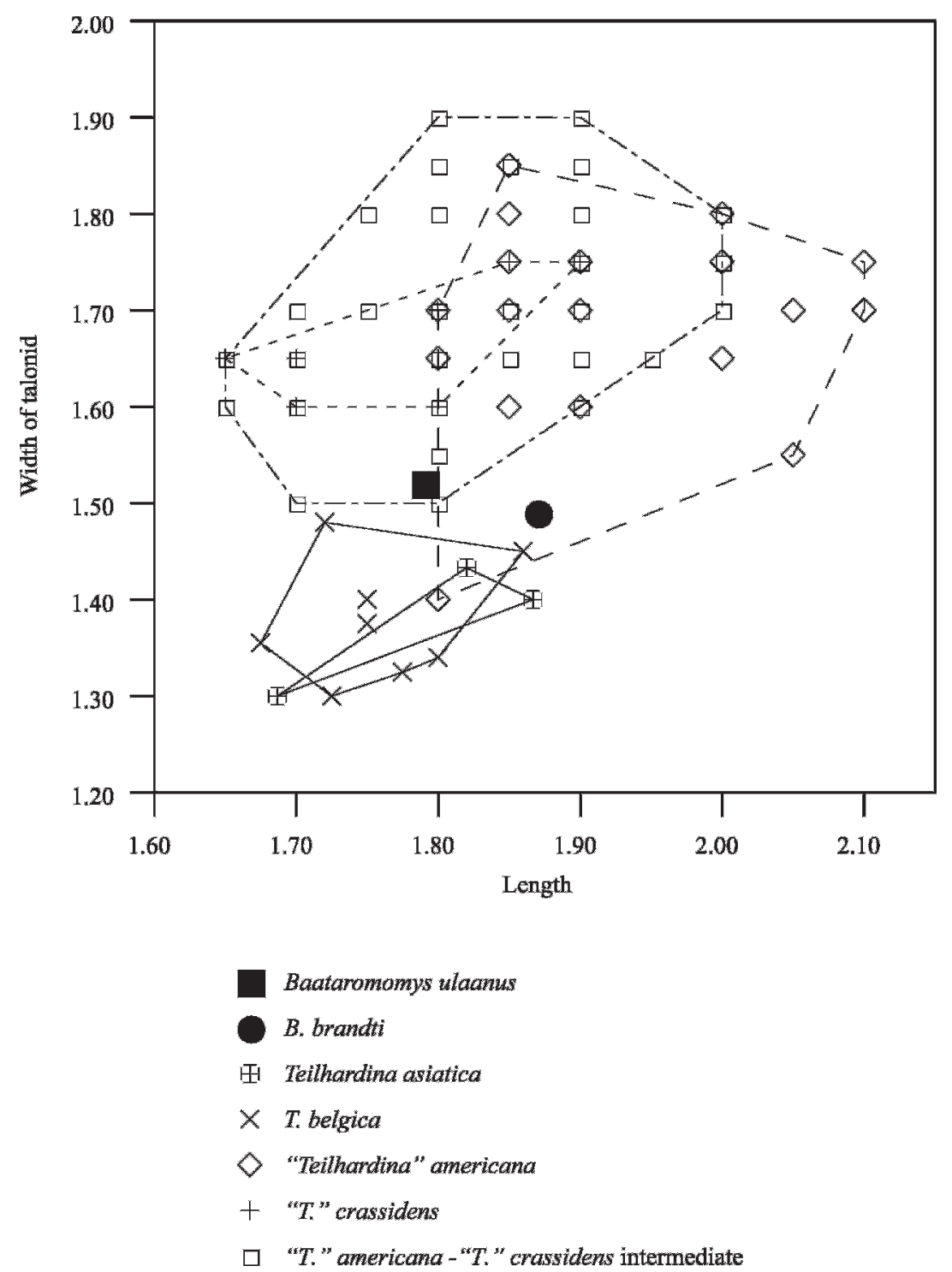

Fig. 2. Size of $\mathrm{m} 2$ in the holotypes of Baataromomys ulaanus, n. gen. et sp. and B. brandti, shown in relation to those of Eurasian Teilhardina and North American "Teilhardina". Measurements of North American "Teilhardina" are taken from Bown and Rose (1987). Vertical and horizontal axes are in millimeters.

This cusp is much smaller and lower than the hypoconid, so that the deepest point of the talonid basin lies lingual to the midline of this structure. The mesiobuccal surface of the entoconid is smooth but concave, forming the distolingual border of the talonid basin. The entocristid is very low and blunt. It does not connect with the weak postmetacristid, leaving the talonid basin open lingually. The lingual arm of the postcristid is insignificant and fuses seamlessly with the transversely elongated hypoconulid. The hypoconulid is worn, exposing the dentine. No significant cusp remains, but it must have been relatively large in its unworn condition, based on the exposed island of dentine. No sulcus is formed 
between the entoconid and hypoconulid, nor between the hypoconulid and hypoconid. A thin but distinct cingulid surrounds the buccal half of the tooth. It originates from the base of the paracristid at its mesiobuccal side, continues distobuccally, envelops the hypoconid, and terminates just below the buccal side of the hypoconulid.

\section{COMPARISONS}

Baataromomys differs enough from other basal omomyids that it is also necessary to compare it with basal adapiforms, such as Donrussellia, as well as the enigmatic primate Altanius (fig. 3).

The trigonid of $\mathrm{m} 2$ in B. ulaanus differs most notably from that of Donrussellia gallica and D. provincialis in the position of the metaconid and the orientation of the protocristid. In Donrussellia, the metaconid of $\mathrm{m} 2$ is more distal in position, which contributes to the relative isolation of this cusp. The relatively distal location of the metaconid in Donrussellia also results in a more oblique, rather than transverse, orientation for the protocristid. In contrast, the metaconid of $\mathrm{m} 2$ in Baataromomys is located only slightly distal to the protoconid, so that the protocristid is nearly transverse. In addition to the wider separation between the paraconid and metaconid on $\mathrm{m} 2$ in Donrussellia compared with Baataromomys, the paraconid in the former genus is relatively larger and its base is not fused with the base of the metaconid. In lingual view, the trigonid of $\mathrm{m} 2$ in Donrussellia is more deeply notched as a result. These lower molar trigonid features distinguish Donrussellia from all omomyids, so the fact that Baataromomys differs from Donrussellia in these respects is unremarkable. On the other hand, there are several ways in which Baataromomys resembles
Donrussellia. For example, both have very broad and shallow talonid basins, with hypoconid and entoconid cusps that are not very elevated. In buccal view, the hypoconid and cristid obliqua on $\mathrm{m} 2$ in Baataromomys are very low, like those of Donrussellia and in contrast to those of Teilhardina. Like Donrussellia, Baataromomys retains a small but distinct hypoconulid on $\mathrm{m} 2$.

Altanius orlovi differs markedly from Baataromomys ulaanus in many aspects of $\mathrm{m} 2$ morphology. In Altanius, $\mathrm{m} 2$ is smaller, relatively narrower, and much higher crowned than that of Baataromomys. The trigonid of $\mathrm{m} 2$ in Altanius is much higher than its talonid, bears three high and conical cusps, and has a more triangular occlusal outline. The paraconid is slightly larger than the metaconid on $\mathrm{m} 2$ in Altanius, and these cusps are fused at their bases to form a lingual pair of trigonid cusps that are higher than the protoconid. The protoconid and hypoconid of Altanius are more pointed and bear more significant buccal ridges, whereas the hypoconulid is much weaker. In Altanius, the cristid obliqua of $\mathrm{m} 2$ is connected to the postvallid below the protoconid-metaconid notch, resulting a very deep hypoflexid. In contrast, the cristid obliqua of Baataromomys is more buccally oriented, thereby forming a very shallow hypoflexid. The talonid basin of Altanius is much deeper and narrower than that of Baataromomys, and its lingual side is closed by a relatively large entoconid and a high entocristid. These important differences in $\mathrm{m} 2$ morphology rule out any possibility of close affinities between Altanius and Baataromomys.

Teilhardina asiatica is the oldest undoubted euprimate known from Asia (Ni et al., 2004). It closely resembles European T. belgica but is morphologically even more primitive. $T$. asiatica and $T$. belgica share some similarities

Fig. 3. Schematic drawings of $\mathrm{m} 2$ morphology in Baataromomys and a comparative sample of early Eocene euprimates. All specimens are scaled to the same mesiodistal length and are depicted in occlusal (left column), buccal (middle column), and lingual (right column) views. Taxa and specimens illustrated are as follows: Baataromomys ulaanus, holotype, IVPP V14614 (A-C); Baataromomys brandti, holotype, UM 99031 (D-F); Teilhardina asiatica, holotype, IVPP V12357 (G-I); "Teilhardina" americana, holotype (reversed), UW 6896 (J-L); Anemorhysis sublettensis, holotype (reversed), USNM19205 (M-O); Tetonoides pearcei, holotype, USNM 22426 (P-R); Steinius vespertinus, USGS 25027 (S-U); Donrussellia provincialis, holotype (reversed), MNHN RI-170 (V-X). Each scale bar indicates $1.00 \mathrm{~mm}$. 
A

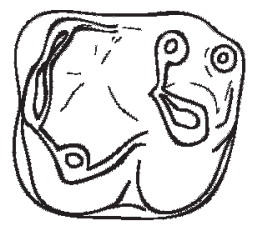

D

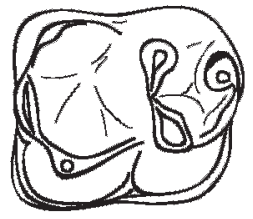

G

$J$
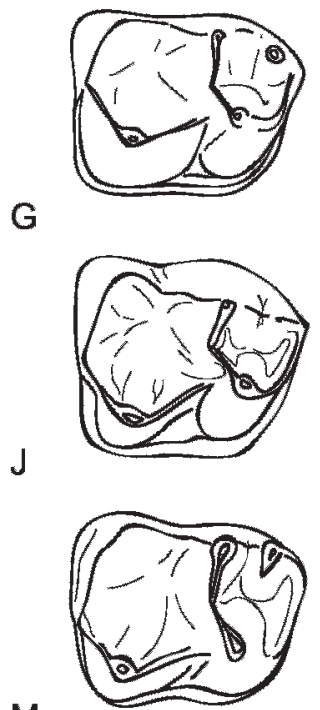

$P$

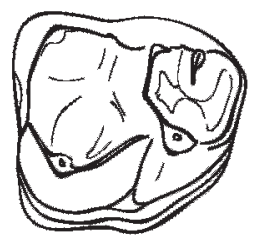

S

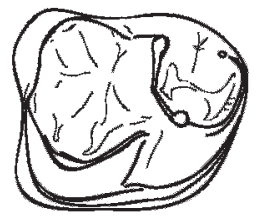

V

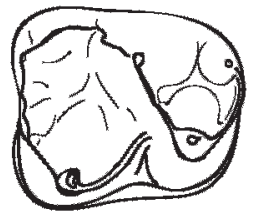

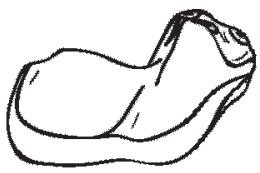

B

C

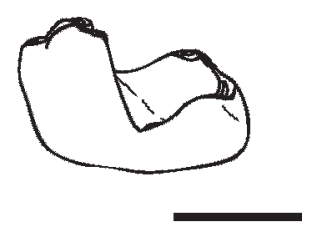

$\mathrm{F}$

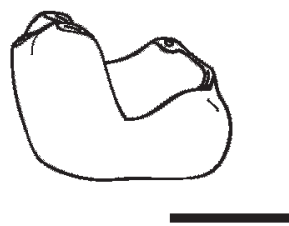

$\mathrm{H}$
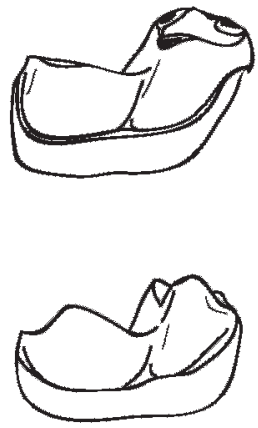

E

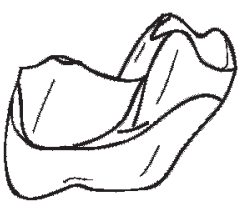

$\mathrm{K}$

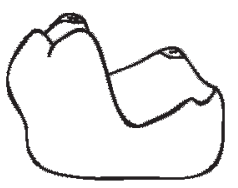

I

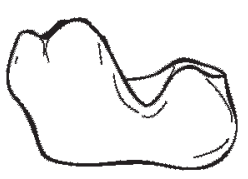

L

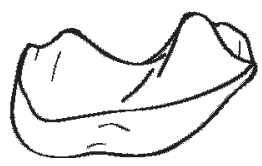

N

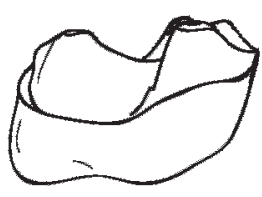

Q

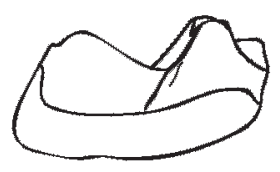

T

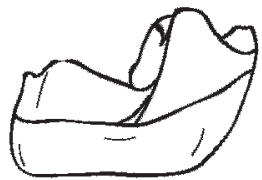

W

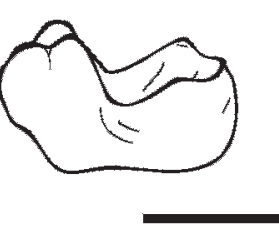

O

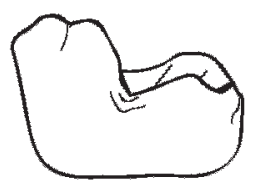

R

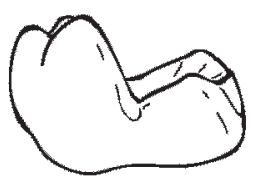

U

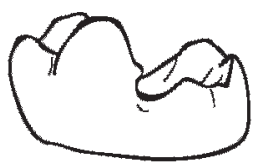

X 
in $\mathrm{m} 2$ morphology with $B$. ulaanus, including a relatively buccal position of the cristid obliqua, a shallow hypoflexid, and a lingually open talonid basin. On the other hand, differences in $\mathrm{m} 2$ morphology between these two species of Teilhardina and $B$. ulaanus are significant. In contrast to the bunodont condition in $B$. ulaanus, the $\mathrm{m} 2$ in $T$. asiatica and $T$. belgica exhibits relatively sharper cusps and more trenchant crests. In occlusal outline, the trigonid of $\mathrm{m} 2$ in $T$. asiatica and $T$. belgica is more triangular than is the case in $B$. ulaanus. While being smaller than the protoconid and metaconid, the paraconid of $\mathrm{m} 2$ in $T$. asiatica and T. belgica is not as reduced as that of $B$. ulaanus. In lingual view, the paraconid on $\mathrm{m} 2$ protrudes mesially in $T$. asiatica and $T$. belgica, but this cusp is fused with the base of the metaconid in B. ulaanus. The talonid of $\mathrm{m} 2$ in $B$. ulaanus differs from that of $T$. asiatica and $T$. belgica in being broader, in having a less elevated hypoconid and cristid obliqua (especially apparent in buccal view), and in having a more prominent hypoconulid.

Kohatius is another early Eocene omomyid genus from Asia. Documented specimens, including a right $\mathrm{m} 1$, a small fragment of a left $\mathrm{p} 4$, a right mandible fragment preserving $\mathrm{p} 4$ and the alveoli for $\mathrm{m} 1-\mathrm{m} 2$, and an isolated left $\mathrm{p} 4$, are from the Kuldana Formation of northern Pakistan (Russell and Gingerich, 1980, 1987; Thewissen et al., 1997). These specimens may represent as many as three different species (Russell and Gingerich, 1980, 1987; Thewissen et al., 1997). Because m2 remains unknown for Kohatius, direct comparisons with Baataromomys are not possible. However, $\mathrm{m} 1$ of Kohatius has taller cusps and stronger crests than do those on $\mathrm{m} 2$ of $B$. ulaanus. Additionally in Kohatius, the paraconid and metaconid are widely separated on $\mathrm{m} 1$, while these cusps (along with the trigonid as a whole) are notable for being closely compressed on $\mathrm{m} 2$ in B. ulaanus. Finally, the $\mathrm{m} 1$ talonid in Kohatius bears a tall and projecting entoconid and a relatively trenchant entocristid, in contrast to the more bunodont conditions that prevail on $\mathrm{m} 2$ in $B$. ulaanus. These morphological distinctions are too great to be attributed to different molar loci alone.
Baataromomys brandti, originally referred to Teilhardina, is the earliest haplorhine primate known from North America (Gingerich, 1993). The holotype of this species is an isolated right $\mathrm{m} 2$ from the earliest Wasatchian (Wa-0) of northwestern Wyoming. This species shares many similarities with $B$. ulaanus. In both taxa, the trigonid of $\mathrm{m} 2$ is mesiodistally narrow; the paraconid, metaconid, and protoconid are rounded; the paraconid is not twinned with the metaconid; the talonid basin is broad and shallow; crests (including the postcristid, cristid obliqua, entocristid, and postmetacristid) are low and blunt; and the hypoconulid is relatively prominent. B. brandti is distinguished from the new taxon in having a slightly stronger paracristid and a paraconid that is located less lingually.

"Teilhardina" americana is a relatively primitive omomyid. Szalay (1982) argued that " $T$." americana is too derived to be referred to Teilhardina. Instead, Szalay (1982) synonymized "T." americana with Anemorhysis tenuiculus. Bown and Rose (1987) maintained a species-level distinction between " $T$." americana and A. tenuiculus, but they acknowledged the close affinities between them, referring both species to Teilhardina. Compared with that of B. ulaanus, $\mathrm{m} 2$ in " $T$." americana has taller cusps and sharper crests. The paraconid of $\mathrm{m} 2$ in " $T$." americana is much larger and protrudes farther mesially than is the case in B. ulaanus, yielding a more triangular occlusal outline for the trigonid. Together, the paraconid and metaconid on $\mathrm{m} 2$ in "T." americana form a massive, bicusped structure on the lingual side of the trigonid, while the reduced paraconid of $B$. ulaanus seems to be merely a vestigial appendage of the metaconid. A subtle but continuous crest connects the apices of the paraconid and metaconid on $\mathrm{m} 2$ in " $T$." americana. This structure becomes much better developed in some younger and more derived North American omomyids, such as Tetonius, Tetonoides, and Trogolemur. In B. ulaanus, no equivalent crest unites the paraconid and metaconid on $\mathrm{m} 2$. The talonid of $\mathrm{m} 2$ in " $T$." americana is much deeper and more fully closed than that of B. ulaanus. On $\mathrm{m} 2$ in " $T$." americana all of the crests surrounding the talonid basin, as well as the hypoconid and 
entoconid, are stronger and more elevated than is the case in B. ulaanus, but the hypoconulid remains much less significant. "T." americana also has a stronger buccal cingulid on $\mathrm{m} 2$ than does $B$. ulaanus.

Steinius has been ranked near the base of the omomyid evolutionary radiation based on its primitive dental anatomy, despite the fact that it occurs stratigraphically well above the earliest North American omomyids (Rose and Bown, 1991; Rose et al., 1994). Both species of Steinius are much larger than B. ulaanus, but these taxa share many features of molar morphology in common. The most significant difference between Steinius and Baataromomys relates to the larger size and more mesial position of the paraconid on $\mathrm{m} 2$ in the former. On the other hand, both taxa possess very broad talonids and relatively low hypoconids and oblique cristids. Cusps and crests are more trenchant in Steinius, whereas the entire crown of $\mathrm{m} 2$ is more bunodont in Baataromomys. Given the large difference in size, the morphological similarities between these taxa are surprising.

\section{DISCUSSION}

Although Baataromomys ulaanus is currently documented by a single $\mathrm{m} 2$, several dental features shared by $B$. ulaanus and B. brandti suggest that they are closely related. These characters include a mesiodistally compressed trigonid, bunodont and rounded protoconid and metaconid cusps, a low talonid with a broad basin, and a prominent hypoconulid. Despite their widely divergent geographic provenances, we think that the combination of these traits indicates that Asian B. ulaanus and North American B. brandti are more closely related to each other than either of them is to other omomyids. We therefore transfer North American "Teilhardina" brand$t i$ to the genus Baataromomys.

B. brandti was previously interpreted as a potential common ancestor for European Teilhardina belgica and North American "Teilhardina" americana (Gingerich, 1993). Based on our morphological comparisons, $B$. brandti shares more features in common with B. ulaanus than it does with any species of Teilhardina. Aside from its small size and relatively simple cusp pattern, Baataromomys lacks any compelling features in common with Teilhardina. Because both of the aforementioned characters are almost certainly primitive for Omomyidae, there is no reason to presume that Baataromomys is more closely related to Teilhardina than it is to Steinius, for example.

Several of the distinctive molar characters of Baataromomys diverge from conditions found in other omomyids, thereby inviting comparisons with other higher level taxa of primates. For example, $\mathrm{m} 2$ of Baataromomys has bunodont and slightly inflated cusps, trigonid and talonid of similar width, a cristid obliqua that reaches the postvallid near the base of the protoconid, a shallow hypoflexid, a moderately developed hypoconulid, and a weak buccal cingulid. These features have often been considered as derived characters among primates, and Kay and Williams (1994) included them in their description of the morphotype of the hypothetical anthropoid ancestor. The potential significance of these characters in Baataromomys is difficult to assess at present, given the very limited anatomical information that is currently available for this taxon. Baataromomys may eventually help to clarify the phylogenetic relationships among basal omomyids and other euprimate clades, but more nearly complete specimens of this taxon will be required to test this possibility.

Along with Teilhardina asiatica, Baataromomys ulaanus documents at least modest diversity in the Asian euprimate radiation at or near the beginning of the Eocene. Such precocious euprimate diversity in Asia is hardly surprising. Indeed, early Asian euprimates must remain significantly undersampled if the phylogenetic evidence pointing toward an Asian origin for this clade is accurate. On the other hand, if $B$. ulaanus and B. brandti prove to be as closely related as current evidence suggests, then Baataromomys would join numerous other mammalian taxa indicating dispersal across the Beringian region near the Paleocene-Eocene boundary (e.g., Beard, 1998; Beard and Dawson, 1999). Finally, the geographic occurrence of Baataromomys ulaanus suggests that forested habitats suitable for small euprimates must have been present, at 
least sporadically, on the Mongolian Plateau during the early Cenozoic.

\section{ACKNOWLEDGMENTS}

We thank Drs. Li Chuankui, Eric Delson, Alfred L. Rosenberger, Richard F. Kay, and an anonymous reviewer for instructive discussion and suggestions, Sun Chengkai, Jin Xun, and Bai Bin for assistance with fieldwork, and Mark A. Klingler for help with illustrations. Financial support from the American Museum of Natural History and the Carnegie Museum of Natural History is gratefully acknowledged. Funding was provided by grants from the National Natural Science Foundation of China (40202003 to X.N. and 40532010 to Y.W.) and U.S. National Science Foundation (BCS 0309800 to C.B. and J.M., and EAR-0120727 to J.M.).

\section{REFERENCES}

Beard, K.C. 1998. East of Eden: Asia as an important center of taxonomic origination in mammalian evolution. In K.C. Beard and M.R. Dawson (editors), Dawn of the Age of Mammals in Asia. Bulletin of Carnegie Museum of Natural History 34: 5-39.

Beard, K.C. 2006. Mammalian biogeography and anthropoid origins. In S. Lehman and J.G. Fleagle (editors), Primate biogeography: progress and prospects: 439-467. New York: Springer.

Beard, K.C., and M.R. Dawson. 1999. Intercontinental dispersal of Holarctic land mammals near the Paleocene-Eocene boundary: paleogeographic, paleoclimatic and biostratigraphic implications. Bulletin de la Société Géologique de France 170: 697-706.

Beard, K.C., and J.-W. Wang. 1995. The first Asian plesiadapoids (Mammalia: Primatomorpha). Annals of Carnegie Museum 64: 1-33.

Bowen, G.J., P.L. Koch, J. Meng, J. Ye, and S.-Y. Ting. 2005. Age and correlation of fossiliferous late Paleocene-early Eocene strata of the Erlian Basin, Inner Mongolia, China. American Museum Novitates 3474: 1-26.

Bown, T.M., and K.D. Rose. 1987. Patterns of dental evolution in early Eocene anaptomorphine primates (Omomyidae) from the Bighorn Basin, Wyoming. The Paleontological Society Memoir 23: 1-162.
Dashzeveg, D., and M.C. McKenna. 1977. Tarsioid primate from the early Tertiary of the Mongolian People's Republic. Acta Palaeontologica Polonica 22: 119-137.

Eizirik, E., W.J. Murphy, M.S. Springer, and S.J. O'Brien. 2004. Molecular phylogeny and dating of early primate divergences. In C.F. Ross and R.F. Kay (editors), Anthropoid origins: new visions: 45-64. New York: Kluwer Academic/ Plenum Publishers.

Gingerich, P.D. 1986. Early Eocene Cantius torresi-oldest primate of modern aspect from North America. Nature 320: 319-321.

Gingerich, P.D. 1993. Early Eocene Teilhardina brandti: oldest omomyid primate from North America. Contributions from the Museum of Paleontology, University of Michigan 28: 321326.

Gingerich, P.D., D. Dashzeveg, and D.E. Russell. 1991. Dentition and systematic relationships of Altanius orlovi (Mammalia, Primates) from the early Eocene of Mongolia. Geobios 24: 637-646.

Godinot, M. 1994. Early North African primates and their significance for the origin of Simiiformes (= Anthropoidea). In J.G. Fleagle and R.F. Kay (editors), Anthropoid origins: 235-295. New York: Plenum.

Hooker, J.J., D.E. Russell, and A. Phélizon. 1999. A new family of Plesiadapiformes (Mammalia) from the Old World lower Paleogene. Palaeontology 42: 377-407.

Kay, R.F., and B.A. Williams. 1994. Dental evidence for anthropoid origins. In J.G. Fleagle and R.F. Kay (editors), Anthropoid origins: 361-445. New York: Plenum.

Meng, J., G.J. Bowen, Y. Jie, P.L. Koch, S.-Y. Ting, Q. Li, and X. Jin. 2004. Gomphos elkema (Glires, Mammalia) from the Erlian Basin: evidence for the early Tertiary Bumbanian Land Mammal Age in Nei-Mongol, China. American Museum Novitates 3425: 1-24.

Miller, E.R., G.F. Gunnell, and R.D. Martin. 2005. Deep time and the search for anthropoid origins. Yearbook of Physical Anthropology 48: 60-95.

Ni, X., Y. Hu, Y. Wang, and C. Li. 2005. A clue to the Asian origin of euprimates. Anthropological Science 113: 3-9.

Ni, X., Y. Wang, Y. Hu, and C. Li. 2004. A euprimate skull from the early Eocene of China. Nature 427: 65-68.

Rose, K.D., and T.M. Bown. 1991. Additional fossil evidence on the differentiation of the earliest euprimates. Proceedings of the National Academy of Sciences 88: 98-101.

Rose, K.D., M. Godinot, and T.M. Bown. 1994. The early radiation of euprimates and the 
initial diversification of Omomyidae. In J.G. Fleagle and R.F. Kay (editors), Anthropoid origins: 1-28. New York: Plenum.

Rose, K.D., and D.W. Krause. 1984. Affinities of the primate Altanius from the early Tertiary of Mongolia. Journal of Mammalogy 65: 721726.

Russell, D.E., and P.D. Gingerich. 1980. Un nouveau primate omomyide dans l'Éocène du Pakistan. Comptes Rendus de l'Académie des Sciences, Paris (série D) 291: 621-624.

Russell, D.E., and P.D. Gingerich. 1987. Nouveaux primates de l'Éocène du Pakistan. Comptes Rendus de l'Académie des Sciences, Paris (série II) 304: 209-214.

Sigé, B., J.-J. Jaeger, J. Sudre, and M. VianeyLiaud. 1990. Altiatlasius koulchii n. gen. et sp., primate omomyidé du Paléocène supérieur du
Maroc, et les origines des euprimates. Palaeontographica (Abteilung A PaleozoologieStrartigraphie A) 214: 31-56.

Szalay, F.S. 1982. A critique of some recently proposed Paleogene primate taxa and suggested relationships. Folia Primatologica 37: 153-162.

Szalay, F.S., and E. Delson. 1979. Evolutionary history of the Primates. New York: Academic Press, $580 \mathrm{pp}$.

Szalay, F.S., A.L. Rosenberger, and M. Dagosto. 1987. Diagnosis and differentiation of the order Primates. Yearbook of Physical Anthropology 30: 75-105.

Thewissen, J.G.M., S.T. Hussain, and M. Arif. 1997. New Kohatius (Omomyidae) from the Eocene of Pakistan. Journal of Human Evolution 32: 473-477. 
Complete lists of all issues of the Novitates and the Bulletin are available at World Wide Web site http://library.amnh.org/pubs. Inquire about ordering printed copies via e-mail from scipubs@amnh.org or via standard mail from: American Museum of Natural History, Library-Scientific Publications, Central Park West at 79th St., New York, NY 10024. TEL: (212) 769-5545. FAX: (212) 769-5009.

@ This paper meets the requirements of ANSI/NISO Z39.48-1992 (Permanence of Paper). 